\title{
Self-attitude and belief in the competitive world of gays
}

\author{
Z. Shaekhov
}

Faculty of Psychology, Lomonosov Moscow State University, Moscow, Russia

The study of people with homosexual and bisexual identity is a relevant topic for Russian psychology, since, on the one hand, this group is very little studied. On the other hand, the anti-propaganda laws adopted in Russia nurture a negative attitude towards the LGB-community, which creates a special social context that requires interpretation [Malysheva, Golynchik, 2013]. The predominance of hegemonic masculinity, stigmatization, discrimination, and other socio-psychological processes adversely affect psychological well-being (PWB), selfacceptance of one's own identity, as well as social belief systems amongst people with LGB-identity.

Goal: to reveal interrelations between self-attitude as to a homosexual and belief in a competitive world in gays. Participants. Participants. In the beginning, the respondents were asked to answer the questions of the questionnaire: age, sex and sexual orientation. 60 homosexuals aged 18-55 years old took part in the research.

Measures. W. Mayfield's homonegativity diagnostic technique in modification of A.Yanykin and A.Nasledov was used to reveal internalized homophobia. J.Duckitt's technique adapted by O.A. Gulevich et al. was used to assess belief in a competitive world.
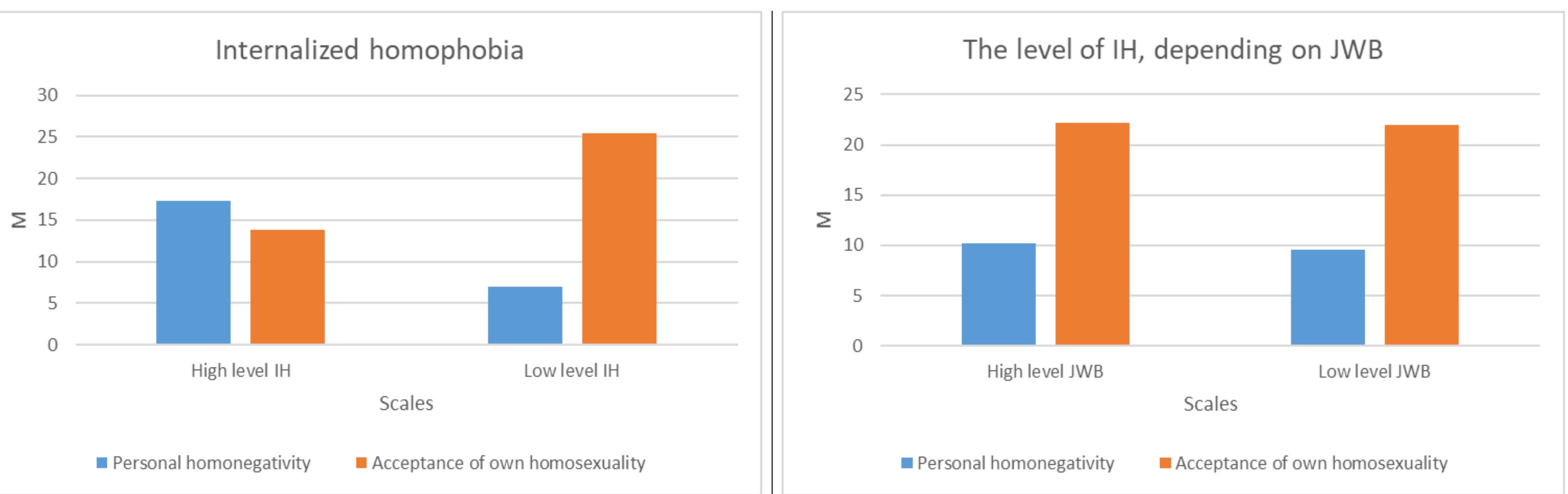

In the course of our research it was determined that the We did not determine reliable differences in scales respondents have low personal homonegativity $(M=9,90)$, «Acceptance of own homosexuality» and «Personal i.e. positive emotions prevail, the respondents are not homonegativity» between believing and not believing in ashamed and consider their sexual orientation positively. a competitive world. their sexual orientation, consider it to be normal and to be an important part of their life, evidence of which is scale «Acceptance of own homosexuality» $(\mathrm{M}=22,08)$.

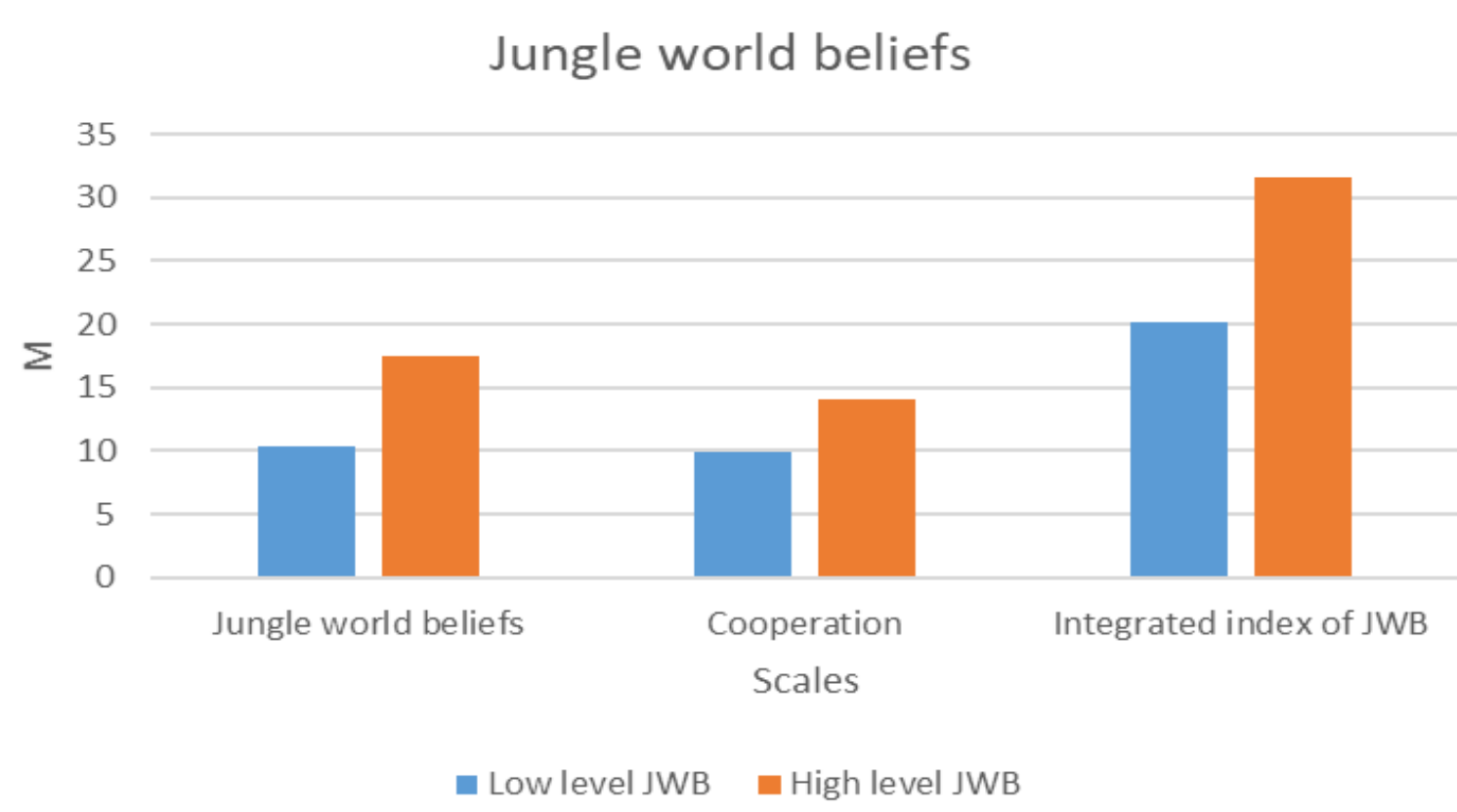

Our respondents do not tend to think, that more successful in the world are those who are able to manage others, i.e. do not tend to perceive social world as competitive $(\mathrm{M}=26,47)$.
Discussion. Our analysis of the obtained results of the Russian sample shows, that self-attitude to oneself as to a homosexual reveals itself positively, i.e. internalized homophobia does not reveal itself, and neither does perception of social world as competitive. At the same become a factor of negative experience of one's homosexuality. It can be connected with the idea that in professional or any other activity, in their opinion, heterosexuals achieve bigger successes than other social groups based on sexual orientation. time perception of social world as competitive may 